\title{
El reduccionismo en medicina
}

\author{
Pablo Young ${ }^{1 *}$ y Pablo R. Justich ${ }^{2}$ \\ ${ }^{1}$ Servicio de Clínica Médica, Hospital Británico de Buenos Aires, Buenos Aires, Argentina; ${ }^{2}$ Hospital La Vega, Murcia, España
}

Hemos leído con atención el trabajo del biólogo Juan Emilio Sala publicado en el Boletín Médico del Hospital Infantil de México ${ }^{1}$. Concordamos con el autor en que el pensamiento complejo y la mirada holística son superadoras de la mirada reduccionista pura. Nos ha parecido clarificador el aporte de ambos casos clínicos como vehículo para transmitir su idea. El autor plantea en sus primeros párrafos que intenta generar debate en el pensamiento de los pediatras y médicos. En nosotros, lo ha generado, por lo que ha cumplido su cometido. Si bien hay cosas con las cuales cuesta coincidir, el debate planteado desde la argumentación invita a mejorar.

En términos generales, observamos un análisis completo y complejo, acorde con lo que el tema merece. También creemos, aun desde las perspectivas ideológicas disímiles de los autores, que la primera parte del artículo, fundado en instrumentos sociológicos muy atractivos, propone una relación casi de causalidad entre la evolución de la división del trabajo de Adam Smith y la evolución de la medicina. Esto nos parece más una muestra de análisis propia del reduccionismo ontológico que cuestiona el artículo, que de una mirada amplia de un fenómeno multifactorial, dinámico y transversal como lo es la evolución del pensamiento en medicina. Podemos compartir o discutir sobre los efectos de la burguesía o el neoliberalismo en lo que hace a modelos de atención o cierta impronta conductual parcial, pero la generalización al pensamiento complejo de nuestro arte/ciencia posee un valor realmente muy limitado. Esta simplificación puede hacernos llegar a conclusiones insuficientemente fundamentadas. Sin duda, coincidimos en que los «excesos" del reduccionismo suponen un riesgo, pero creemos que estos obedecen más a la necesidad de ajuste en ciertas perspectivas que a una consecuencia social directamente relacionada con las diferentes corrientes ideológicas, ya sea liberal, marxista, etcétera².

El saber humano es acumulativo. Al principio de los tiempos, el hombre podía alardear de tener conocimientos de casi todo. A medida que esos conocimientos se fueron haciendo más complejos por la suma de descubrimientos, su interrelación y la aparición de innumerables hipótesis y críticas, cada ciencia dejó de ser parte de un todo y comenzó la compartimentalización ${ }^{3}$. Lo vemos en el derecho, la medicina, la física, la biología, la ciencia política, etcétera. A medida que todo se va tornando más complejo, se fragmenta el estudio y la investigación, pero ninguna de estas partes olvida que forma parte de un universo más amplio que integran todas las ciencias. ¿Qué sería la medicina si todos fuésemos médicos generales e hiciéramos de todo (clínica, neurocirugía, partos, etcétera), y qué pasaría si los biólogos no se especializaran? ¿Todos sabrían todo de todas las especies abordadas?

El autor Juan Emilio Sala se muestra partidario de los "clichés", hablando del modelo médico "hegemónico" (MMH) y de la "profesionalización" de la medicina como si fuera bueno volver a las hierbas curativas y a las prácticas de la medicina precolombina - e imagina que, en la actividad médica en los grandes centros, sobre todo de EE.UU., se «jibariza» a los enfermos, se les estudia por partes, se les fragmenta a través de la exagerada especialización. El autor nos conduce a

\section{Correspondencia:}

*Pablo Young

E-mail: pabloyoung2003@yahoo.com.ar
Fecha de recepción: 19-04-2018

Fecha de aceptación: 15-05-2018 DOI: 10.24875/BMHIM.M18000031
Disponible en internet: 10-08-2018 Bol Med Hosp Infant Mex. 2018;75:260-262 www.bmhim.com

1665-1146/@ 2018. Hospital Infantil de México Federico Gómez, impreso por Permanyer México SA de CV, todos los derechos reservados. 
través del $\mathrm{MMH}$, introduciendo una cuestión semántica por lo menos cuestionable, no porque no la defina y cite correctamente, sino porque termina haciendo una generalización epistemológica que, a nuestro parecer, es injusta e inconsistente. El MMH nos parece un término infelizmente acuñado e irresponsablemente difundido, que no resiste siquiera un análisis semántico. Este concepto, del que se ha abusado como tópico por mucha gente desde fuera de nuestra profesión como una crítica lapidaria, da a entender que la hegemonía del pensamiento médico (es decir la gran mayoría de los médicos) no es humanista, no reivindica la mirada holística ni el enfoque ecológico de nuestros pacientes. Asume, además, que médico equivale a biologicista, y esta concepción es errónea. Creemos que es una de las secuelas de la medicina basada en la evidencia (MBE) tan explotada como doctrina en la actualidad.

El autor supone que hay hiperespecialización, como si los especialistas, aun los más fanáticos, no supieran que la parte es, por su propia definición, solo parte de un todo. Sería absurdo que alguien no lo supiera. Sin embargo, el autor atribuye la fragmentación únicamente al sistema liberal "globalizado", ignorando que cuando existe, es transversal. La consideración de que este fenómeno se origina en el carácter «burgués» de la medicina occidental nos parece una mirada parcial, segmentaria y excesivamente reduccionista de este fenómeno, teniendo en realidad más coincidencias con la multiplicación del conocimiento, su interacción, socialización y amplificación, que con el modo en que se relacionan las diferentes sociedades con los medios de producción. Dice Juan Emilio Sala que el proceso de especialización comenzó en la década de 1950, y no es así. Siempre hubo necesidades de especialización, dependiendo de cada especialidad. Lo que sucedió después de la Segunda Guerra Mundial fue el auge de la tecnología al servicio de la medicina, y esto multiplicó la necesidad de especializarse. Esto traía sus costos, que en general se pretende trasladar a quien consume sus beneficios. Pero todo fue un proceso que no evoluciona a saltos, sino que es más bien como una secuencia de sucesos con tendencias muchas veces seculares, influenciadas por infinidad de causas (interés, azar, vocación).

Dice el autor que la especialización médica "conduciría a la descuartización del cuerpo a extremos inimaginables...». Esto nunca sucedió en ningún país civilizado, independientemente de la ideología imperante en los mismos.

Pensar que el modelo económico que describió Adam Smith haya influido en la medicina, formateándola, es bastante curioso; hasta parece original. Lo cierto es que la economía fue tomando su forma de acuerdo con lo que sucedía en el mundo, en la política, en las relaciones internacionales, en las sociedades. La evolución de la medicina sufrió el mismo proceso, pero en forma autónoma ${ }^{4}$.

Habla de «la lógica inherente al capitalismo» como si fuera una descalificación, lo cual es materia opinable, y creemos que excede el análisis del tema central. Sostenemos que, como en otros órdenes de las ciencias, ya sean exactas, naturales o sociales, hay bases racionales o de realismo crítico que aportan mucha riqueza a su evolución. ¿Conoce otra lógica que no sea la aristotélica tomista o la lógica formal?

Las críticas terminantes de Sala al llamado Círculo de Viena son difíciles de sostener. Lo mismo que la Escuela de Frankfurt, tuvo sus aciertos y sus errores, pero protagonizados por cada uno de quienes lo integraban. Incluso, suponer que el Círculo de Viena era el fruto de un pensamiento homogéneo es excesivo. Los muchos que fracasaron dentro de esos conglomerados de pensadores fue porque se ataron a ideologías que no parecen haber tenido el éxito deseado. Lo que es cierto es que, si despertaran hoy quienes integraron aquel Círculo, se asombrarían ante la sola posibilidad de que se los tomara como exponentes de un pensamiento único.

Quizá por ello se acude a los términos «reduccionistas" que nada implican en términos prácticos. Se olvida aquel principio que dice que «la claridad es la cortesía del filósofo». Cuando se explica algo, esto debe poder sostenerse por la realidad: es lo que Karl R. Popper (1902-1994) llamaba «contrastabilidad». Las afirmaciones del autor colisionan con la realidad, quizás por expresar un dogmatismo muy estricto.

Cuando Juan Emilio Sala habla del «reduccionismo» y el método cartesiano como si fuera un error fundamental, se enfrenta con la historia misma de la investigación científica. Tan mal no le ha ido a la civilización con estos mecanismos, y si bien es enorme el camino que falta por recorrer - nadie sabe cuánto y cuál es la meta final-, el autor intenta descalificar lo hecho porque no cuadra con lo que él supone deberían ser las exigencias (que nadie ha descubierto cuáles son), lo cual parece exagerado. Lo que debería exigirse a los artículos es que ilustren, que aclaren, no que confundan, sobre todo cuando ya hay bastante confusión en muchos espíritus.

Como mencionó el autor respecto de su experiencia con los médicos y el diagnóstico, y extrapolando a Miguel Ángel hablando de La Piedad, ¿cómo puedo 
hacer una escultura? Simplemente, retirando del bloque de mármol todo lo que no es necesario ${ }^{5}$. Así, para llegar al diagnóstico, al igual que Miguel Ángel hace una escultura, se requieren ciertos pasos de razonamiento que deben entrenarse y que forman parte del pensamiento complejo ${ }^{3,6}$. Ese pensamiento se ejercita durante la residencia, que creemos que debería ser obligatoria y, como tal, el único camino para obtener la habilitación para ejercer la profesión. Además, otros factores deben ser tomados en cuenta al momento de la consulta, como las interferencias (teléfonos) y el factor tiempo, que es clave para poder desarrollar el pensamiento complejo pretendido $0^{7,8}$.

En relación al primer caso clínico mencionado, no hay duda de que el excelente criterio del hepatólogo infantil permitió reducir riesgos y anticipar el diagnóstico, pero no debemos olvidar la sucesión de procesos reductivos que permitieron llegar al mismo: el bebé ha sido atendido por un neonatólogo (subespecialidad de la pediatría, a su vez especialidad de la medicina) que lo derivó a un subespecialista en hepatología infantil. Podríamos preguntarnos si, en ausencia de estas derivaciones a subespecialidades (reduccionismo), podría haberse llegado oportunamente al diagnóstico desde la medicina general.

Por último, nos gustaría apelar al segundo caso clínico que Sala reporta cuando hace mención del daño que, a nivel neurobiológico, hace para el individuo el conocer una estadística de supervivencia. Si bien es cierto que el uso inapropiado de la estadística puede causar daños en quienes no dominan conceptos como medidas de dispersión y otros, hay que reconocer por otro lado que, si son bien interpretadas, resultan de gran utilidad para tomar decisiones. El error conceptual es pensar que los valores estadísticos son un instrumento de comunicación directa para con el paciente. Nosotros, los médicos, debemos utilizar ese instrumento en un contexto y con un conocimiento que permita darle valor real a un número frío. Aquí es donde la MBE fracasa de manera rotunda: adapta el sujeto al número y no usa el número al servicio del sujeto con sus propias singularidades. Nosotros debemos valernos de la estadística para nuestra comprensión y traducir el mensaje de esos valores a los pacientes en términos comprensibles y útiles para él mismo, siempre y cuando puedan asimilarlos.

La evolución de la medicina y la salud pública con el progreso de sus especialidades proveen de una descomposición analítica resultante en una herramienta muy eficaz, que no solo no «jibariza» el conocimiento, sino que potencia la comprensión global del paciente, sumando perspectivas en todos los planos posibles y acercándonos a una salud mejor para nuestros pacientes.

\section{Bibliografía}

1. Sala JE. La jibarización del logos: cómo el reduccionismo médico puede matar. Bol Med Hosp Infant Mex. 2017;74:154-63.

2. Greene JA, Loscalzo J. Putting the patient back together-Social Medicine, Network Medicine, and the Limits of Reductionism. N Engl J Med. 2017;377:2493-9.

3. De Vito EL. La medicina "al borde del caos". Vida, entropía y complejidad. Medicina (B Aires). 2016;76:45-54.

4. Justich PR. ¿Medicina basada en el mercado o medicina basada en el paciente? Arch Argent Pediatr. 2015;113:146-53.

5. García C. El mármol que sobra. 2018 Feb 18. En: Blog Mi médico de cabecera [Internet]. Disponible en: https://mimedicodecabecera.blogspot. com.ar/2018/02/el-marmol-que-sobra.html.

6. D'Negri CE, De Vito EL. Introducción al razonamiento aproximado: lógica difusa. Rev Arg Med Resp. 2006:4:126-36.

7. Losasso A, Rubinstein E. El diagnóstico va construyéndose con el tiempo. Rev Hosp Ital B Aires. 2006;26:103-6.

8. Justich ZP. 6 minutos. Arch Argent Pediatr. 2018;116:e70-4. 